\title{
PENGARUH KUALITAS PELAYANAN TERHADAP KEPUASAN MAHASISWA DI PTS X SURABAYA
}

\author{
Rachma Rizqina Mardhotillah, Reizano Amri Rasyid \\ Fakultas Ekonomi dan Bisnis \\ Universitas Nahdlatul Ulama Surabaya \\ e-mail: rachma.rizqina@unusa.ac.id,reizano21@unusa.ac.id
}

\begin{abstract}
Higher Education Institution (PT) X is a private university located in Surabaya. In order for its existence and quality to be guaranteed, PTS X must conduct research on student satisfaction. This study aims to examine the effect of service quality on student satisfaction at X University in Surabaya. The independent variable in this study is the quality of service with tangible, reliability, responsiveness, assurance, empathy, and dependent variable indicators in this study is the satisfaction of students at X University in Surabaya. This research is a type of quantitative research with a survey method, where researchers who analyze the numbers obtained from the survey results in the form of distributing questionnaires to the respondents. The research sample in this study were 200 PTS students in Surabaya. The sampling technique in this study was non-probability sampling using quota sampling technique. The results of the analysis show that service quality with tangible indicators has a positive and significant effect on satisfaction. Service quality with the indicator of reliability has a positive and not significant effect on student satisfaction. Service quality with responsive indicator has a positive and significant effect on student satisfaction. Service quality with the assurance indicator has a positive and not significant effect on student satisfaction. Service quality with empathy indicators has a positive and significant effect on student satisfaction at University $X$ in Surabaya.
\end{abstract}

Keywords: service quality, student satisfaction

\section{PENDAHULUAN}

Salah satu kondisi yang dihadapi dunia pendidikan tinggi Indonesia saat ini merupakan masalah persaingan yang bersifat lokal, regional, dan global. Perguruan tinggi (PT) di Indonesia, baik yang berstatus negeri atau swasta tidak hanya bersaing dengan PT lokal tetapi juga berbagai institusi Perguruan Tinggi di tingkat internasional. Dari data Statistik Pendidikan Perguruan Tinggi Kementerian Pendidikan Nasional menyebutkan pada 2018 jumlah unit perguruan tinggi yang terdaftar mencapai 4.186 unit. Angka ini didominasi oleh perguruan tinggi swasta (PTS) yang mencapai 3.136 unit. Sedangkan perguruan tinggi negeri (PTN) menjadi unit paling sedikit, yakni 122 unit. Sisanya adalah perguruan tinggi agama dan perguruan tinggi di bawah kemen- terian atau lembaga negara dengan sistem kedinasan.

Dalam konteks perguruan tinggi (PT), kepuasan konsumen cenderung berada pada mahasiswa yang dalam hal ini bertindak sebagai stakeholder utama. Kepuasan mahasiswa saat ini sudah dianggap sebagai hal yang berperan penting dalam menilai kualitas layanan dari sebuah perguruan tinggi dan merupakan salah satu faktor penting dan krusial pada kemajuan suatu perguruan tinggi.

Banyak hal yang membuat kecenderungan tersebut, salah satu di antaranya adalah bahwa PT kini perlahan telah bergeser menjadi sebuah sektor yang kompetitif, di mana PT telah mengalami hukum permintaan dan penawaran seperti layaknya sebuah perusahaan atau organisasi korporasi. Hal ini membuat PT harus mempersiap- 
kan suatu keunggulan strategi mereka agar dapat bersaing secara kompetitif yang berbeda (diferensiasi) dengan PT yang lain. Seperti yang dikatakan oleh Kotler (2006:105) menyatakan bahwa "Salah satu cara menempatkan sebuah perusahaan jasa lebih unggul daripada pesaingnya ialah dengan memberikan pelayanan yang lebih bermutu dibandingkan dengan para pesaingnya. Pengelolaan kualitas layanan yang baik dan benar dapat menjadi daya tarik bagi mahasiswa.

Jain et al. (2011) mengemukakan bahwa institusi akademik membutuhkan inovasi berkelanjutan, diversitas struktur, dan menemukan cara baru untuk memberikan pelayanan kepada pelanggannya secara lebih efektif. Hal ini ditujukan untuk memperoleh keuntungan kompetitif dengan institusi akademik lainnya.

Perguruan Tinggi (PT) X merupakan salah satu Perguruan Tinggi Swasta yang terletak di Surabaya. Pada perkembangannya, PTS. X berkembang pesat menjadi salah satu PTS favorit di area Surabaya. Pada usia 4 tahun, PTS X sudah terakreditasi Institusi B, dan dalam waktu yang tidak lama hampir semua Program Studi yang dimiliki sudah terakreditasi B dari BAN PT dan LAMPT-Kes. Supaya eksistensi dan kualitas yang dimiliki terjamin, PTS X harus menjalankan riset terhadap kepuasan mahasiswa. Berdasarkan definisi ini, maka diharapkan dengan kualitas layanan yang baik dan professional akan menimbulkan kepuasan pelanggan. Konsep kualitas pelayanan yang sangat popular adalah konsep SerQual yang dikembangkan oleh Parasuraman, Berry, dan Zeithml (1988: 16).

Indeks kepuasan konsumen/mahasiswa yang akan diperoleh dari penelitian ini nantinya dapat menjadi masukan bagi PTS X untuk pengembangan pelayanan dan atau pengembangan proses penyelenggaraan pendidikan. Dalam hal ini mahasiswa sebagai sumber dari inovasi dan sebagai partner dalam usaha pengembangan.

\section{PENGEMBANGAN HIPOTESIS}

Kualitas Pelayanan terhadap Kepuasan Mahasiswa

Dalam sebuah penilaian kualitas pelayanan jasa dan penilaian kepuasan dari sisi pelanggan, telah didapatkan konsensus bahwa ekspektasi pelanggan merupakan faktor penting sebagai perbandingan dalam penilaian kualitas juga kepuasan pelanggan.

Jika kualitas pelayanan yang diberikan oleh penyedia jasa memuaskan, maka hal ini memengaruhi konsumen dalam pembelian jasa tersebut kembali, begitupun sebaliknya. Parasuraman et al. (1988) telah melakukan berbagai penelitian terhadap beberapa jenis jasa, sehingga didapatkan 5 dimensi karakteristik utama yang digunakan dalam penilaian kualitas pelayanan. 5 dimensi yang dikenal juga sebagai Q-Rater ini dijadikan dalam 1 metode yang disebut sebagai metode service quality (servqual). Q-Rater tersebut adalah (1) tangible, (2) reliability, (3) responsiveness, (4) assurance, dan (5) empathy.

Tingkat kepuasan pelanggan yang ada dalam sebuah penilaian institusi perguruan tinggi sangatlah penting. Karena terciptanya kepuasan pelanggan dapat memberikan beberapa manfaat, seperti akan terciptanya hubungan yang baik antara institusi dengan para pelanggan, sehingga dapat tercipta loyalitas pelanggan yang tentunya dapat menguntungkan bagi institusi, pelanggan yang dimaksud adalah mahasiswa dan mahasiswi di Perguruan Tinggi X Surabaya. Menurut (Wijaya, 2011) pada dasarnya tujuan perusahaan ataupun institusi adalah menciptakan kepuasan pelanggan.

Hal ini didukung oleh penelitian oleh Mayasari (2017) dengan judul penelitian Analisis Kualitas Pelayanan SIAKAD Terhadap Kepuasan Mahasiswa UIN Raden Intan Lampung yang menemukan hasil bahwasanya kualitas pelayanan SIA- 
KAD mempunyai pengaruh terhadap kepuasan mahasiswa dan Niswati (2016) dengan judul Pengaruh Pelayanan Administrasi Akademik Terhadap Kepuasan Mahasiswa pada Fakultas Ekonomi dan Bisnis pada Fakultas Ekonomi dan Bisnis Islam UIN Alaudin Makasar dengan hasil penelitian pelayanan administrasi akademik mempunyai pengaruh yang signifikan terhadap kepuasan mahasiswa pada Fakultas Ekonomi dan Bisnis Islam UIN Alauddin Makassar.

Berdasarkan uraian di atas bisa ditarik hipotesis sebagai berikut.

Hý: Kualitas pelayanan dengan indikator tangible, reliability, responsiveness, assurance, empathy berpengaruh signifikan terhadap kepuasan mahasiswa-mahasiswi di PTS X Surabaya.

\section{METODE PENELITIAN}

\section{Populasi, Sampel, Teknik Pengambilan Sampel}

Metode pengumpulan data pada penelitian ini adalah dengan menyebarkan kuesioner. Populasi penelitian ini adalah mahasiswa dan mahasiswi PTS X Surabaya. Sampel penelitian dalam penelitian ini adalah mahasiswa/mahasiswi PTS X di Surabaya sebanyak 200 orang.

Teknik pengambilan sampel pada penelitian ini non-probability sampling dengan menggunakan teknik quota sampling. Quota sampling adalah suatu metode sampling dengan cara membagi populasi menjadi cluster-cluster lalu setiap cluster harus diwakili dengan proporsi yang sama dengan populasinya.

Variabel dalam penelitian ini ada dua yaitu kualitas layanan dengan indikator tangible, reliability, responsiveness, assurance, empathy, dan kepuasan mahasiswa di PTS X Surabaya.

Teknik analisis data pada penelitian ini menggunakan metode structural equation mod- eling-partial least square (SEM-PLS) dengan pendekatan warpPLS. Analisis SEM-PLS ini digunakan untuk mengetahui pengaruh variabel laten eksogen, yaitu kualitas pelayanan dan variabel laten endogen adalah kepuasan mahasiswa-mahasiswi di PTS X Surabaya.

\section{Variabel Penelitian dan Definisi Operasional Variabel}

Variabel penelitian pada dasarnya adalah segala sesuatu yang berbentuk apa saja yang ditetapkan oleh peneliti untuk dipelajari sehingga diperoleh informasi tentang hal tersebut (Sugiono, 2018). Variabel dalam penelitian ini dapat diklasifikasikan menjadi tiga. (1) Variabel independen (bebas) dalam penelitian ini adalah kualitas pelayanan, kualitas pelayanan merupakan setiap tindakan atau perbuatan yang ditawarkan oleh sebuah pihak kepada pihak lain, yang pada dasarnya bersifat tidak wujud atau biasa disebut dengan (intengibel) dan tidak mengakibatkan kepemilikan apa pun terhadap sesuatu (Kotler, 2009). Kualitas pelayanan dalam penelitian ini diukur dengan menggunakan lima indikator, yaitu tangible merupakan meliputi fasilitas fisik, perlengkapan dan penampilan. Realibility merupakan kemampuan memberikan pelayanan sesuai dengan yang dijanjikan dan dapat diandalkan. Responsivenes merupakan kesediaan dan kesiapan petugas untuk membantu dan memberikan layanan dengan tanggap. Assurance yaitu dapat dipercaya, bebas dari keraguan-keraguan. Dan yang terakhir yaitu empathy meliputi hubungan berkomunikasi, perhatian pribadi dan memahami kebutuhan mahasiswa. (2) Variabel dependen (terikat) dalam penelitian ini adalah kepuasan, menurut Tjiptono (2012) menjelaskan bahwa kepuasan pelanggan bukanlah konsep absolut, melainkan relatif atau tergantung pada apa yang diharapkan pelanggan. 
Teknik Analisis Data

\section{Evaluasi Model Pengukuran WarpPLS}

Evaluasi model dalam PLS meliputi 2 tahap, yaitu yang pertama dengan menggunakan evaluasi outer model, outer model digunakan untuk menentukan spesifikasi hubungan antara variabel laten dengan indikatornya. Evaluasi outer model meliputi convergent validity, discriminant validity, dan yang terakhir composite reliability. Evaluasi inner model atau yang disebut dengan model struktural yaitu digunakan untuk menentukan hubungan antar-konstruk laten dengan konstrak laten lainnya. Evaluasi inner model meliputi uji kecocokan model (model fit), path coefficient, dan $\mathrm{R}^{2}$.

\section{HASIL DAN PEMBAHASAN}

\section{Evaluasi Model Pengukuran (Outer Model)}

a. Convergent Validity (Validasi Konvergen)

Tabel 1 Hasil Output Combined Loading and Cross-Loading

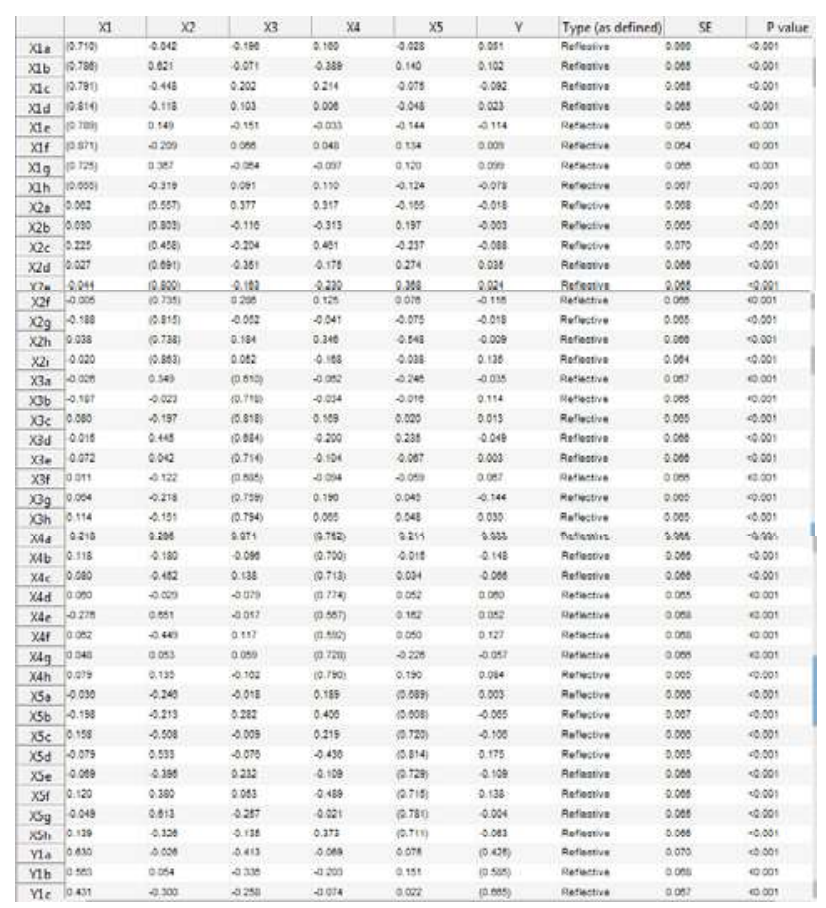

Sumber: Hasil Output WarpPLS 6.0 (2019)
Berdasarkan hasil output combined loading and cross loading dapat disimpulkan bahwasanya ada beberapa indikator yang tidak memenuhi kriteria convergent validity, hal ini dikarenakan jumlah nilai loading dari beberapa indikator lebih kecil dari 0.70 , sehingga beberapa indikator yang masih belum memenuhi nilai loading harus di eliminasi.

Tabel 2

Hasil Output Combined Loading and Cross Loading Setelah Penghapusan Beberapa Indikator

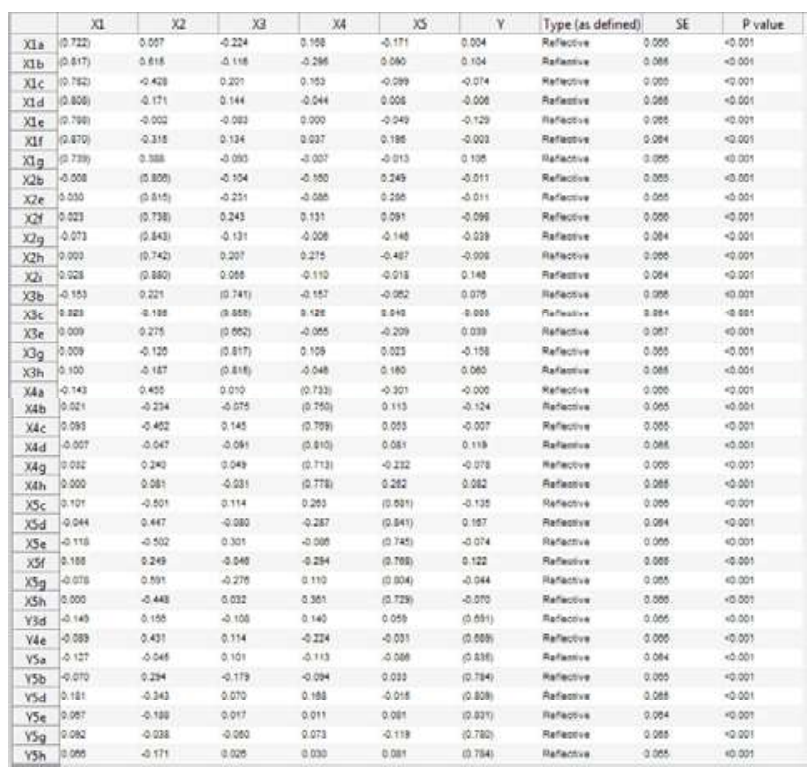

Sumber: Hasil Output WarpPLS 6.0 (2019)

Berdasarkan tabel di atas setelah penghapusan beberapa indikator dapat disimpulkan bahwasanya semua indikator sudah memenuhi kriteria convergent validity, hal ini dikarenakan jumlah nilai loading seluruh indikator lebih besar dari 0.70 dan nilai p-value kurang dari 0.05 .

\section{b. Discriminant Validity (Validasi Diskriminan)}

Discriminant validit dinilai dari cross loading pengukuran dengan konstruk. Terdapat dua cara untuk mengevaluasi terpenuhnya validitas diskriminan yaitu dengan cara: (1) dengan melihat loading konstruk laten, yang digunakan 
untuk memprediksi indikatornya lebih baik daripada konstruk lainnya. Dan apabila korelasi konstruk dengan pokok pengukuran (setiap indikator) lebih besar daripada ukuran konstruk lainnya maka validasi diskriminan terpenuhi. (2) dapat digunakan untuk menganalisis discriminant validity yaitu dengan kriteria AVE.

\section{1) Melihat loading ke konstrak lain}

Di bawah ini merupakan hasil output dari olah data WarpPLS 6.0, seperti pada tabel 4.9 yang disajikan dalam tabel sebagai berikut.

Tabel 3 Nilai Loading Konstruk Laten Indikator ke Konstruk Lainnya

\begin{tabular}{|c|c|c|c|c|c|c|c|c|}
\hline & $\mathrm{X}_{1}$ & X2 & $x_{3}$ & $x_{4}$ & $\times 5$ & $Y$ & Type (as defined & \\
\hline$x 1 a$ & $(0.722)$ & 0.057 & -0.224 & 0.188 & -0.171 & 0.004 & Reflective & 0.088 \\
\hline $\mathrm{x} 1 \mathrm{~b}$ & $(0.817)$ & 0.515 & -0.116 & -0.295 & 0.090 & 0.104 & Reflective & 0.085 \\
\hline $\mathrm{x} 1 \mathrm{c}$ & $(0.782)$ & -0.428 & 0.201 & 0.183 & -0.099 & -0.074 & Reflective & 0.065 \\
\hline X1d & $(0.808)$ & -0.171 & 0.144 & -0.044 & 0.008 & -0.006 & Reflective & 0.085 \\
\hline Xle & $(0.788)$ & -0.002 & -0.083 & 0.000 & -0.049 & -0.129 & Reflective & 0.085 \\
\hline XIf & $(0.870)$ & -0.315 & 0.134 & 0.037 & 0.195 & -0.003 & Reflective & 0.064 \\
\hline $\mathrm{xlg}$ & $(0.739)$ & 0.388 & -0.093 & -0.007 & -0.013 & 0.108 & Reflective & $0.08 \varepsilon$ \\
\hline$x_{2 b} b$ & -0.008 & $(0.808)$ & -0.104 & -0.180 & 0.249 & -0.011 & Reflective & 0.085 \\
\hline$x_{2 e}$ & 0.030 & (0.815) & -0.231 & -0.085 & 0.205 & -0.011 & Reflective & 0.085 \\
\hline$x 2 f$ & 0.023 & $(0.738)$ & 0.243 & 0.131 & 0.091 & -0.098 & Reflective & 0.088 \\
\hline$\times 2 g$ & -0.073 & $(0.843)$ & -0.131 & -0.005 & -0.145 & -0.039 & Reflective & 0.084 \\
\hline$\times 2 \mathrm{~h}$ & 0.003 & $(0.742)$ & 0.207 & 0.275 & -0.487 & -0.008 & Reflective & 0.068 \\
\hline$x_{2 i}$ & 0.028 & (0.880) & 0.055 & -0.110 & -0.018 & 0.148 & Reflective & 0.084 \\
\hline X3b & -0.153 & 0.221 & $(0.741)$ & -0.157 & -0.062 & 0.076 & Reflective & $0.08 e$ \\
\hline$x 3 c$ & 0.023 & -0.100 & $(0.866)$ & 0.128 & 0.040 & -0.003 & Reflective & 0.064 \\
\hline$\times 3 e$ & 0.009 & 0.275 & $(0.662)$ & -0.065 & -0.209 & 0.039 & Reflective & 0.087 \\
\hline$\times 3 g$ & 0.009 & -0.126 & $(0.817)$ & 0.109 & 0.023 & -0.158 & Reflective & 0.085 \\
\hline$x 3 \mathrm{~h}$ & 0.100 & -0.187 & (0.815) & -0.048 & 0.160 & 0.080 & Reflective & 0.085 \\
\hline$x_{4 a}$ & -0.143 & 0.455 & 0.010 & $(0.733)$ & -0.301 & -0.006 & Reflective & 0.086 \\
\hline X4b & 0.021 & -0.234 & 0.075 & $(0.750)$ & 0.113 & -0.124 & Reflective & 0.065 \\
\hline $\mathrm{x} 4 \mathrm{c}$ & 0.093 & -0.462 & 0.145 & (0.769) & 0.053 & -0.007 & Reflective & 0.065 \\
\hline x4d & -0.007 & -0.047 & -0.091 & $(0.810)$ & 0.081 & 0.119 & Reflective & 0.065 \\
\hline$\times 4 \mathrm{~g}$ & 0.032 & 0.240 & 0.049 & $(0.713)$ & -0.232 & -0.078 & Reflective & 0.086 \\
\hline $\mathrm{x} 4 \mathrm{~h}$ & 0.000 & 0.081 & -0.031 & $(0.778)$ & 0.252 & 0.082 & Reflective & 0.065 \\
\hline$\times 5 c$ & 0.101 & -0.501 & 0.114 & 0.263 & $(0.681)$ & -0.135 & Reflective & 0.008 \\
\hline$\times 5 \mathrm{~d}$ & -0.044 & 0.447 & -0.080 & -0.287 & $(0.841)$ & 0.167 & Reflective & 0.064 \\
\hline$\times 5 \mathrm{e}$ & -0.118 & -0.502 & 0.301 & -0.083 & $(0.745)$ & -0.074 & Reflective & $0.08 \varepsilon$ \\
\hline$\times 5 f$ & 0.155 & 0.249 & -0.048 & -0.294 & $(0.788)$ & 0.122 & Reffective & 0.085 \\
\hline$\times 5 \mathrm{~g}$ & -0.078 & 0.591 & -0.276 & 0.110 & $(0.804)$ & -0.044 & Reflective & 0.085 \\
\hline$\times 5 \mathrm{~h}$ & 0.000 & -0.448 & 0.032 & 0.381 & $(0.729)$ & -0.070 & Reflective & $0.08 \varepsilon$ \\
\hline Y3d & -0.149 & 0.156 & -0.108 & 0.140 & 0.059 & $(0.891)$ & Reflective & $0.08 \varepsilon$ \\
\hline $\mathrm{Y}_{4 \mathrm{e}}$ & -0.059 & 0.431 & 0.114 & -0.224 & -0.031 & $(0.889)$ & Reflective & $0.08 \varepsilon$ \\
\hline Y5o & -0.127 & -0.045 & 0.101 & -0.111 & -0.005 & $(0.825)$ & Retlostive & 0.084 \\
\hline Y5b & -0.070 & 0.294 & -0.179 & -0.094 & 0.033 & (0.784) & Reflective & 0.085 \\
\hline Y5d & 0.181 & -0.343 & 0.070 & 0.168 & -0.015 & $(0.809)$ & Reflective & 0.065 \\
\hline V5e & 0.067 & -0.188 & 0.017 & 0.011 & 0.081 & (0.831) & Reflective & 0.084 \\
\hline $\mathrm{Y} 5 \mathrm{~g}$ & 0.092 & -0.038 & -0.050 & 0.073 & 0.119 & $(0.780)$ & Reflective & 0.068 \\
\hline Y5h & 0.068 & -0.177 & 0.026 & 0.020 & 0.081 & $(0.784)$ & Reflective & 0.005 \\
\hline
\end{tabular}

Sumber: Hasil Output WarpPLS 6.0 (2019)

Berdasarkan hasil di atas, dari keseluruhan indikator sudah memenuhi kriteria discriminant validity, hal ini dikarenakan nilai loading dari setiap indikator lebih besar dari nilai konstruk lainnya.

\section{c. Composite Reliability}

Pengujian dalam tahap selanjutnya adalah uji realibilitas konstruk yang dapat diukur menggunakan dua kriteria yaitu composite reliability dan cronbach's alpha. Suatu konstruk dapat dikatakan reliabel apabila nilai composite realibility $>0.70$.

Tabel 4 Output Latent Variabel Coefficient

\begin{tabular}{|l|c|c|c|c|c|c|}
\hline & $\mathrm{X} 1$ & $\mathrm{X} 2$ & $\mathrm{X} 3$ & $\mathrm{X} 4$ & $\mathrm{X} 5$ & $\mathrm{Y}$ \\
\hline R-Squared & & & & & & -0.031 \\
\hline Composite reliab & 0.921 & 0.917 & 0.886 & 0.891 & 0.893 & 0.924 \\
\hline Cronbach's alpha & 0.899 & 0.891 & 0.838 & 0.853 & 0.855 & 0.905 \\
\hline Avg. Var. Extrac. & 0.625 & 0.649 & 0.611 & 0.577 & 0.582 & 0.604 \\
\hline Full Collin. VIF & 1.845 & 2.630 & 1.884 & 1.846 & 2.439 & 1.023 \\
\hline Q-squard & & & & & & 0.125 \\
\hline
\end{tabular}

Sumber: Hasil Output WarpPLS 6.0 (2019)

Berdasarkan hasil olah data di atas dapat disimpulkan bahwasanya hasil dari composite reliab dan cronbach's alpha dari keseluruhan variabel sudah memenuhi composite reliability. Hal ini dikarenakan nilai composite reliability dan cronbach's alpha dari seluruh variabel lebih besar dari 0.70 .

\section{2) Evaluasi Model Struktural (Inner Model)}

Selanjutnya adalah tahap melakukan evaluasi model struktural (inner model) yang meliputi uji kecocokan model (model fit), path coefficient, dan $\mathrm{R}^{2}$. Pada uji kecocokan model terdapat tiga indeks pengujian, yaitu average path coefficient (APC), average R-squared (ARS), dan average varians factor (AVIF) dengan kriteria APC dan ARS diterima dengan syarat p-value $<0.05$ dan AVIF lebih kecil dari 5 (Mahfud Sholihin dan Dwi Ratmono, 2013). 
Tabel 5 Hasil Output Model Fit Indices

\begin{tabular}{|c|c|c|c|c|}
\hline & Indeks & $\begin{array}{c}p- \\
\text { value }\end{array}$ & Kriteria & Keterangan \\
\hline APC & 0.130 & 0.020 & $\mathrm{P}>0.05$ & Diterima \\
\hline ARS & 0.031 & 0.171 & $\mathrm{P}>0.05$ & Ditolak \\
\hline AVIF & 2.567 Good if $<5$ & & AVIF $<5$ & Diterima \\
\hline
\end{tabular}

Sumber: Hasil Output WarpPLS 6.0 (2019)

Berdasarkan tabel di atas dapat disimpulkan hasil dari model fit indices adalah untuk hasil nilai APC dinyatakan diterima, dan hasil dari ARS dinyatakan ditolak, hal ini dikarenakan nilai ARS lebih besar dari 0.05, dan untuk nilai AFIV dinyatakan diterima hal ini dikarenakan hasil nilai AVIF sebesar 2.567 yaitu lebih kecil dari 5 dan bisa dinyatakan dengan hasil Good if.

\section{3) Hasil Uji Hipotesis}

Pengujian hipotesis ini juga dimasukkan karena digunakan untuk membuktikan kebenaran dugaan penelitian atau hipotesis. Hasil korelasi antara konstruk dapat diukur dengan melihat path coefficient dan tingkat signifikannya yang kemudian dibandingkan dengan hipotesis penelitian. Tingkat signifikan yang dipakai dalam penelitian ini sebesar 5\%.

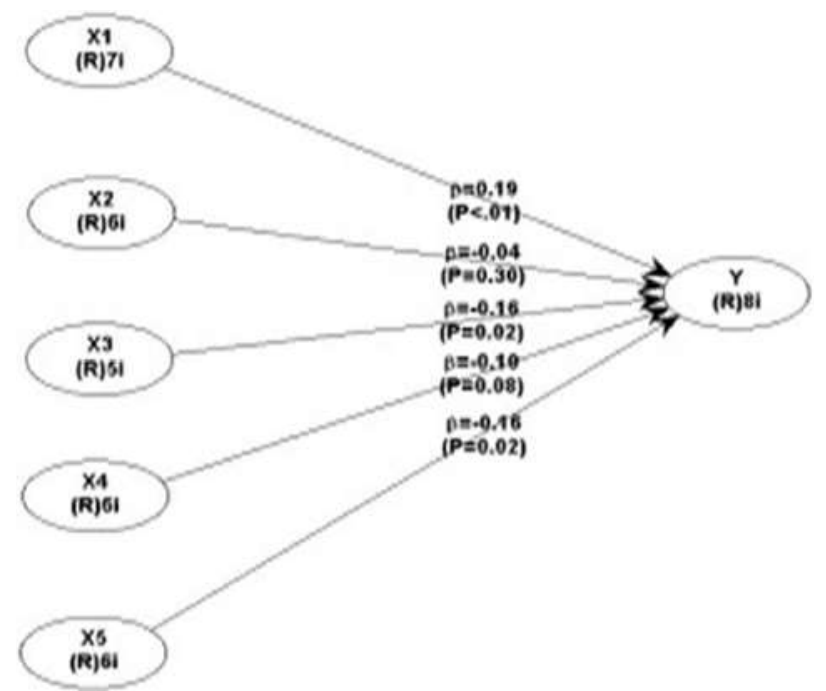

Gambar 1 Model Penelitian

Sumber: Hasil Output WarpPLS 6.0 (2019)
Kualitas Pelayanan terhadap Kepuasan Mahasiswa-Mahasiswi di PTS X Surabaya

Hý: Kualitas pelayanan dengan indikator tangible, reliability, responsivenes, assurance, empathy berpengaruh signifikan terhadap kepuasan mahasiswa-mahasiswi di PTS X Surabaya.

Berdasarkan hasil Gambar 1 menunjukkan variabel kualitas pelayanan dengan indikator tangible terhadap kepuasan mahasiswa memiliki nilai p-value sebesar 01 , nilai path coefficient sebesar 0.19 dan nilai $\mathrm{F}^{2}$ sebesar 0.058, yang artinya kualitas pelayanan dengan indikator tangible berpengaruh positif dan signifikan terhadap kepuasan mahasiswa. Indikator tangible dalam memengaruhi kepuasan mahasiswa sebesar 5,8\% dan selebihnya sebesar 94,2\% dipengaruhi oleh variabel lain. Hal ini dikarenakan apabila Tangible pada sebuah instansi atau sebuah perusahaan semakin buruk maka akan menyebabkan ketidakpuasan konsumen, sehingga akan mengakibatkan menurunnya kepuasan mahasiswa pada Universitas X di Surabaya.

Variabel kualitas pelayanan dengan indikator reliability terhadap kepuasan mahasiswa memiliki nilai p-value sebesar 0,30 , nilai path coefficient sebesar 0.04 dan nilai $\mathrm{F}^{2}$ sebesar 0.009, yang artinya kualitas pelayanan dengan indikator realibility berpengaruh positif dan tidak signifikan terhadap kepuasan mahasiswa. Indikator reliability dalam memengaruhi kepuasan mahasiswa hanya sebesar $0,9 \%$ selebihnya sebesar 99,1\% dipengaruhi oleh variabel lain. Hal ini dikarenakan apabila petugas pada Universitas X di Surabaya kurang baik dalam memberikan pelayanan kepada mahasiswa maka mahasiswa akan semakin tidak percaya dengan kemampuan petugas dalam melayani sehingga akan menurunnya kepuasan terhadap mahasiswa di Universitas X di Surabaya. 
Variabel kualitas pelayanan dengan indikator responcivenes terhadap kepuasan mahasiswa memiliki nilai $p$-value sebesar 0.02 , nilai path coefficient sebesar 0.16 dan nilai $\mathrm{F}^{2}$ sebesar 0.032, yang artinya kualitas pelayanan dengan indikator responsiveness berpengaruh positif dan signifikan terhadap kepuasan mahasiswa. Dan indikator responsiveness dalam memengaruhi kepuasan mahasiswa sebesar 3,2\% dan selebihnya sebesar 96,8\% dipengaruhi oleh variabel lain. Hal ini dikarenakan apabila petugas mampu memberikan respons yang baik terhadap mahasiswa maka mahasiswa akan merasa diperhatikan sehingga akan meningkatkan kepuasan terhadap mahasiswa di Universitas X di Surabaya.

Variabel kualitas pelayanan dengan indikator assurance terhadap kepuasan mahasiswa memiliki nilai $p$-value sebesar 0.08 , nilai path coefficient sebesar 0.10, dan nilai $\mathrm{F}^{2}$ sebesar 0.012, yang artinya kualitas pelayanan dengan indikator assurance berpengaruh positif dan tidak signifikan terhadap kepuasan mahasiswa. Indikator assurance dalam memengaruhi kepuasan mahasiswa hanya sebesar $1,2 \%$ dan selebihnya sebesar 98,8\% dipengaruhi oleh variabel lain. Hal ini dikarenakan apabila keterampilan karyawan dalam memberikan informasi, kemampuan dalam memberikan keamanan dalam memanfaatkan jasa yang ditawarkan kurang baik maka akan menurunkan rasa kepercayaan mahasiswa kepada Universitas X di Surabaya.

Variabel kualitas pelayanan dengan indikator empathy terhadap kepuasan mahasiswa memiliki nilai $p$-value sebesar 0.02 , nilai path coefficient sebesar 0.16, dan nilai $\mathrm{F}^{2}$ sebesar 0.036, yang artinya kualitas pelayanan dengan indikator empathy berpengaruh positif dan signifikan terhadap kepuasan mahasiswa. Indikator empathy dalam memengaruhi kepuasan mahasiswa hanya sebesar $3,6 \% \%$ dan selebihnya sebesar
96,4\% dipengaruhi oleh variabel lain. Hal ini dikarenakan apabila petugas atau karyawan mampu menunjukkan rasa empati yang lebih baik terhadap mahasiswa maka mahasiswa akan merasa nyaman sehingga kepuasan mahasiswa juga akan meningkat.

\section{KESIMPULAN}

Berdasarkan hasil penelitian yang telah dilakukan maka dapat disimpulkan hasil penelitian sebagai berikut.

1. Kualitas pelayanan dengan indikator tangible berpengaruh positif dan signifikan terhadap kepuasan mahasiswa di Universitas X di Surabaya.

2. Kualitas pelayanan dengan indikator reliability berpengaruh positif dan tidak signifikan terhadap kepuasan mahasiswa di Universitas $\mathrm{X}$ di Surabaya.

3. Kualitas pelayanan dengan indikator responsiveness berpengaruh positif dan signifikan terhadap kepuasan mahasiswa di Universitas $\mathrm{X}$ di Surabaya.

4. Kualitas pelayanan dengan indikator assurance berpengaruh positif dan tidak signifikan terhadap kepuasan mahasiswa di Universitas $\mathrm{X}$ di Surabaya.

5. Kualitas pelayanan dengan indikator empathy berpengaruh positif dan signifikan terhadap kepuasan mahasiswa di Universitas X di Surabaya.

\section{SARAN}

Penelitian ini tentu masih banyak kekurangan dan kelemahan, untuk itu dibutuhkan perbaikan-perbaikan yang dapat membangun. Saran yang dapat diberikan untuk penelitianpenelitian selanjutnya adalah sebagai berikut. 


\section{Bagi Objek Penelitian}

Saran untuk objek penelitian yang digunakan dalam penelitian ini yaitu diharapkan agar supaya kualitas pelayanan pada Universitas X di Surabaya ini lebih ditingkatkan kembali sehingga konsumen atau mahasiswa merasa terpuaskan.

\section{Bagi Akademisi}

Bagi peneliti selanjutnya disarankan agar mengembangkan penelitian ini dengan menambah variabel-variabel yang masih belum ada di dalam penelitian ini sehingga dapat menghasilkan penelitian yang lebih baik lagi.

\section{DAFTAR RUJUKAN}

Jain, S., et al. 2011. The Role of Calcium, Magnesium, and Zinc in Preeclampsia. An Abstract. Biological Trace Element Research, 133(2): 162-167.

Kotler, Philip. 2006. Manajemen Pemasaran, Edisi Pertama. Jakarta: PT Indeks Kelompok Gramedia.

Kotler, Phillip. 2009. Manajemen Pemasaran, Edisi 13. Jakarta: Erlangga
Mahfud Sholihin dan Dwi Ratmono. 2013. Analisis SEMPLS dengan WarpPLS 3.0 untuk Hubungan No-Linier dalam Penelitian Sosial Bisnis. Yogyakarta: Penerbit ANDI. Mayasari, Rika. 2017. Analisis Kualitas Pelayanan SIAKAD Terhadap Kepuasan Mahasiswa UIN Raden Intan Lampung.

Niswati. 2016. Pengarub Pelayanan Administrasi Akademik Terhadap Kepuasan Mahasiswa pada Fakultas Ekonomi dan Bisnis Pada Fakultas Ekonomi dan Bisnis Islam UIN Alaudin Makasar.

Parasuraman, Valarie A. Zeithaml, and Leonard L. Berry. 1988. Servqual: A Multiple-Item Scale for Measuring Consumer Perceptions of Service Quality. Journal of Retailing, Vol. 64 (1) pp. 12-37.

Parasuraman, et, al. 1988. Zeithmal and Bitner 1996. Konsep dan Teknik Pengukuran Kualitas Produk Jasa. Kajian Bisnis dan Manajemen, Vol. 4, No I.

Sugiono. 2018. Metode Penelitian Kuantitatif, Kualitatif, dan R\&DD. Bandung: Alfabeta.

Wijaya, T. 2011. Manajemen Kualitas Jasa. Jakarta: PT. Indeks. 